\section{Estudo \\ Ecidebate}

em Testão

Plamejamento
Revista Estudo \& Debate, Lajeado, v. 25, n. 3, 2018. ISSN 1983-036X

DOI: http://dx.doi.org/10.22410/issn.1983-036X.v25i3a2018.1894

\title{
PRODUZIR PARA O AUTOCONSUMO: UMA ANÁLISE DA AGRICULTURA FAMILIAR NO MUNICÍPIO DE TEUTÔNIA/RS
}

\author{
Junior Hagemann ${ }^{1}$, Cíntia Agostini ${ }^{2}$
}

\begin{abstract}
Resumo: A produção de alimentos no mercado brasileiro é prioritariamente atendida pela agricultura familiar. No Vale do Taquari, e especificamente no município de Teutônia/RS, prevalecem a produçáo e o processamento de alimentos em propriedades de caráter familiar, que, além de atender a demanda por alimentos, produz parte do que é necessário para o consumo próprio. Essa produção é denominada para autoconsumo e objetiva tanto reduzir os custos de aquisição como privilegia a segurança alimentar. Assim, este estudo objetivou analisar quais os fatores que determinam a produçáo para o autoconsumo nas propriedades familiares de Teutônia/RS. Enquanto metodologia, esta pesquisa é qualitativa e quantitativa. A análise de dados se deu pela mensuração da representatividade na renda da produçáo e análise de conteúdo das entrevistas. Como resultado constatou-se que essa a produção para autoconsumo está diminuindo nas propriedades, sendo mantida essa prática parcialmente devido à segurança alimentar e à renda.
\end{abstract}

Palavras-chave: Agricultura familiar. Autoconsumo. Renda das propriedades rurais. Segurança alimentar.

\section{TO PRODUCE TO THE SELF-CONSUMPTION: AN ANALYSIS OF FAMILY FARMING IN TEUTÔNIA CITY - RS}

\begin{abstract}
The production of food in the Brazilian market is primarily served by family farming. In the Taquari Valley, and specifically in the city of Teutônia/RS, the production and processing of foods prevail in properties of family character, which, attending the market needs and producing the necessary to the families involved. This production know as self-consumption and intends to reduce outlays in acquisition and provide feeding safety. This study intend to analyze which factors determine the production to self-consumption in familiar farms in Teutônia/RS. To do so, was used a qualitative research as the methodology. The data analysis was made with the mensuration of the representativity in the income of production and content analysis of the interviews. As result was verified that the production for self-consumption is decreasing in the properties, being maintained that practice partially due to the alimentary safety and to the income.
\end{abstract}

Keywords: Family farming. Self-consumption. Rural proprieties income. Food safety.

1 Administrador com Habilitação em Negócios Agroindustriais pela Univates.

2 Economista, Mestre em Ambiente e Desenvolvimento (Univates), Doutora em Desenvolvimento Regional (Unisc). 


\section{Introduçáo}

A produção de alimentos, apesar das percepçóes diversas, é indispensável a todos. De forma geral, o agronegócio é visto a partir das grandes produçóes exportadoras, no entanto a maior parte do que é consumido no Brasil é produzida por sujeitos vinculados à agricultura familiar.

Conforme Flores, Ries e Antunes (2006), o setor agropecuário sempre era tido como um segmento da economia mais atrasado em relação à utilização de novas tecnologias e das técnicas administrativas. Contudo, a partir da década de 1970, mudanças profundas ocorreram na agricultura brasileira.

Essas mudanças se deram por ações políticas, sociais, econômicas e culturais, que transformaram a velha característica do setor rural brasileiro denominado pequena agricultura, ou, anteriormente, agricultura camponesa - em que os produtores produziam seu próprio alimento e, inclusive, aproveitavam o excesso da produçáo para trocar com seus vizinhos -, em amplo processo de mercantilização da agricultura, que transformou esta última, deixando de lado a enxada, a tração animal, a carroça, a colheita manual, entre outros, para dar lugar a novas tecnologias de produção, sendo adotadas novas práticas e novos meios para produzir.

Segundo Silva (2011), essas mudanças ocasionadas no meio rural com o uso de agrotóxicos e o desmatamento modificaram o entendimento da forma de fazer a agricultura e de produzir alimentos. Essa modernização foi impulsionada, principalmente, pelo poder público, por meio de incentivos para a aquisiçấo de novas tecnologias e novos equipamentos.

$\mathrm{Na}$ agricultura familiar, os produtores produziam alimentos para a venda e mantinham produção para autoconsumo. No decorrer dos anos, houve questionamentos sobre a possibilidade de a produção com vistas à geração de excedente poder eliminar a produção para autoconsumo. No entanto, a agricultura brasileira não eliminou essa característica, porém, na agricultura empresarial, na qual a propriedade não é familiar, sua gerência e o trabalho não são desempenhados pelos membros familiares e a produção para o autoconsumo não é destacada.

Conforme Grisa e Schneider (2008), a produção para o autoconsumo é um tema sem muita importância e pouco discutido pela maioria dos pesquisadores e gestores públicos, mas que desenvolve importante papel como renda não monetária, que fortalece a segurança alimentar, abordando questóes de sociabilidade e de identidade social.

Assim, a produção para o autoconsumo, um assunto pouco abordado por autores e nem discutido pela cadeia do agronegócio, é relevante, principalmente nas propriedades familiares, destacando sua função como geradora de renda, ou seja, a possibilidade de não haver gastos familiares para o consumo de certos bens produzidos na propriedade; como aspecto que viabiliza a sociabilidade, isto é, a interação com os vizinhos; e produção que promove a segurança alimentar, quando possibilita conhecer a origem do produto a ser consumido.

Nessas condiçóes, o presente artigo analisa os principais fatores que determinam a produção de alimentos para autoconsumo nas propriedades rurais no município de Teutônia/RS e analisadas as perspectivas das agricultoras para tal produção. Para tanto, além 
desta introdução, e da conclusão no capítulo 7, o artigo discute teoricamente a agricultura familiar no capítulo 2 e a produção para autoconsumo no capítulo 3, para, na sequência, indicar os procedimentos metodológicos, capítulo 4, e finalizar com as análises da pesquisa de campo nos capítulos 5 e 6 e seus subcapítulos.

\section{A agricultura familiar e a produção para autoconsumo}

Até a metade do século passado era considerado de agricultura familiar um "estabelecimento rural no qual a gerência da propriedade é feita pela própria família que a ocupa. Neste estabelecimento, o trabalho, em sua maior parte, é desempenhado pela família” (FEIJÓ, 2011, p. 129).

Ainda conforme Feijó (2011), a contratação de mão de obra de terceiros ocorria somente esporadicamente e, caso isso ocorresse, o número de trabalhadores temporários não podia superar $25 \%$ do total de trabalhadores familiares.

Em 1964, por meio da Lei no 4.504, a definição da agricultura familiar já era mencionada, porém só nos anos mais recentes o conceito se tornou popular. A lei descrevia:

[...] é o imóvel que, direta e pessoalmente explorado pelo agricultor e sua família, lhes absorva toda a força de trabalho, garantindo-lhes a subsistência e o progresso social e econômico, com área máxima fixada para cada região e tipo de exploração, e eventualmente trabalhado com ajuda de terceiros (FEIJÓ, 2011, p. 129).

Schneider (2003) e Feijó (2011) destacam que a expressão agricultura familiar começou a tomar forma no âmbito social e político brasileiro a partir da criação do Programa Nacional de Fortalecimento da Agricultura Familiar (Pronaf). O Estado brasileiro criou este programa nos anos 1990 com a finalidade de prover crédito agrícola para os pequenos produtores rurais de forma mais estável, pois, antes da referida década, a cada ano, os agricultores sofriam para se manter na atividade com as diversas políticas públicas dos governos não implementadas ou alteradas.

Em 24 de julho de 2006, foi aprovada a Lei no 11.326 , conhecida como a Lei da Agricultura Familiar. A lei aprovada estabeleceu novas definiçôes para o que se conhece como agricultor familiar, o qual deve atender aos seguintes critérios:

\footnotetext{
[...] não detenha, a qualquer título, área maior que 4 (quatro) módulos fiscais;

[...] utilize predominantemente mão de obra da própria família nas atividades econômicas do seu estabelecimento ou empreendimento;

[...] tenha renda familiar predominante originada de atividades econômicas vinculadas ao próprio estabelecimento ou empreendimento;

[...] dirija seu estabelecimento ou empreendimento com sua família (BRASIL, 2015).
}

A partir de dados apurados no Instituto Nacional de Colonização e Reforma Agrária - Incra (2015), módulo fiscal é uma unidade de medida, também expressa em hectares, cuja representatividade é determinada por município. Com base em informações da Associação Riograndense de Empreendimentos de Assistência Técnica e Extensão Rural - Emater-RS (2013), o município de Teutônia/RS estipulou que cada módulo fiscal corresponde a 18 
hectares. Então, para que a propriedade rural se enquadre como sendo uma propriedade familiar, não poderá possuir mais que 72 hectares, além dos outros fatores já mencionados.

A agricultura familiar, segundo Schneider (2003, p. 32), compreende "grupos sociais com pequenas extensóes de terra e que utilizam fundamentalmente o trabalho da família na execução dos processos produtivos".

A definição de agricultura familiar por Abramovay (2003) considera que a gestão, a propriedade e grande parte do trabalho devem ser oriundas de membros da família, desde que tenham laços de sangue ou de casamento entre si. Para esse autor, é compreensível a não unanimidade da definição, visto que para cada finalidade pode haver interpretaçóes diversas.

Para Lamarche (1993, p. 15), “a exploração familiar [...], corresponde a uma unidade de produção agrícola onde propriedade e trabalho estão intimamente ligados à família”. A inter-relação desses fatores origina conhecimentos mais concretos e complexos a respeito da transmissão do patrimônio, ou seja, a questão da sucessão familiar e a reprodução da exploração.

A definiçáo do conceito de agricultura familiar ainda é, contudo, cercada por indecisōes, incertezas. Nesse sentido, Feijó (2011, p. 160) menciona que a "agricultura familiar trata-se de uma forma organizacional do setor na qual o agente preponderante do processo de produção é a própria família responsável pelo estabelecimento em questão".

Nessas condiçôes, em conformidade com o Instituto Brasileiro de Geografia e Estatística - IBGE (2015), mais de 80\% das propriedades rurais brasileiras são de agricultura familiar, as quais são responsáveis por 70\% dos alimentos produzidos no Brasil. Esses dados refletem a relevância da produção para o consumo interno a partir da agricultura familiar.

\section{3. $O$ autoconsumo nas propriedades rurais}

A produção para autoconsumo da agricultura familiar, tema do presente artigo, possui características diferenciadas da produção das comunidades primitivas ${ }^{3}$ e mesmo da produçáo camponesa ${ }^{4}$, existentes ao longo do tempo e em diversos territórios. A produçáo para o autoconsumo na agricultura familiar, conforme expresso anteriormente neste artigo, é interpretada por Gazolla, Grisa e Schneider (2010) como uma ferramenta utilizada pelas unidades familiares com o objetivo de conseguir seu alimento. Esse alimento segue direto da unidade de produção para a mesa da família, sem ter intermediaçáo acarretando no seu valor.

3 As características das comunidades primitivas, segundo Rezende filho (2000) eram de pequenas comunidades, que possuíam características nômades, coletavam frutos e caçavam. Assim, a dinâmica social era imposta pela natureza e caracterizavam sociedades igualitárias e solidárias. Por fim, economicamente caracterizada pela não geração de excedente econômico.

4 Andrade et al. (1990) definem unidade camponesa como sendo um tipo de unidade de produção que se caracteriza pelo baixo capital de implantação. Uma característica predominante é o trabalho não remunerado, que significa mão de obra familiar. Nesse tipo de unidade, a comercialização é baixa, uma vez que se produz somente o que será consumido pela família. 
Nesse sentido, Garcia Jr. (1989, p.127) explicita que, “ao autoconsumir diretamente durante parte do ano, as unidades familiares diminuem o tempo em que estấo expostas à flutuação dos preços pagos ao consumidor, reduzindo os momentos em que são apenas consumidoras".

A produção para o autoconsumo também é denominada como mínimo calórico, mínimo alimentar vital, consumo doméstico e produção "pro gasto" - denominação esta mais conhecida popularmente. Essas são algumas denominaçóes para a produção para o autoconsumo, contudo esta produção é definida como sendo produzida pela família para consumo próprio (GRISA; SCHNEIDER, 2008).

Esses autores ressaltam que o principal objetivo do agricultor é garantir o bem-estar de sua família por meio da produção de autoconsumo. Para Gazolla e Schneider (2007), os agricultores, ao realizarem suas atividades e tarefas, organizam-se pensando sempre no equilíbrio familiar, ou seja, entre o consumo e o trabalho da família, observando o tamanho e a composição do grupo familiar (número de consumidores e trabalhadores diferenciados por sexo e idade), e ainda as necessidades que resultam.

Ainda, segundo Gazolla e Schneider (2007, p. 98), "o autoconsumo é a esfera da unidade doméstica que vai dar a base e o lastro para que haja a diversificação das estratégias de vivência na agricultura familiar". Com essa citação, esses autores expóem que, com o fortalecimento da produção de autoconsumo na propriedade, os membros poderão desenvolver outras atividades na propriedade para obtenção de outras fontes de renda. Assim, sem o autoconsumo, a renda e as atividades que eram desenvolvidas com a produçáo de autoconsumo serão gastas para a aquisição de mercadorias, pagando os preços de mercado aos itens necessários para o consumo alimentar do grupo doméstico.

Gazolla e Schneider (2007, p. 101) ainda complementam que "a produção para o autoconsumo gera a autonomia do agricultor familiar por manter interna a unidade produtiva, a principal esfera responsável pela reproduçáo do grupo doméstico, fazendo com que o grupo dependa cada vez menos das condiçóes externas à unidade de produção para se reproduzir socialmente". Assim, o agricultor não corre risco com as mudanças, flutuaçóes das condiçóes de troca no mercado, ou seja, não ficando refém do ambiente social e econômico no qual está inserido.

Para exemplificar, esta autonomia do agricultor familiar, a alternatividade, é uma possibilidade de o produtor optar em querer vender sua produçáo ou ser consumida pelo grupo familiar. Conforme Garcia Jr. (1983), dentro da alternatividade existem duas condiçôes de troca:

Se os preços dos produtos estáo altos, o pequeno produtor pode vender a sua produção, guardando o dinheiro para as épocas em que baixarem os preços. Consumirá de sua própria produção apenas o necessário na época em que está vendendo. Se os preços estão baixos e tiver dinheiro, o pequeno produtor adquire o produto necessário ao consumo familiar. Com os preços baixos, caso não tenha dinheiro, lança mão do próprio produto na obtenção do necessário ao consumo familiar. Assim, tanto a comercialização da própria produção quanto o autoconsumo destes produtos levam em consideração a flutuação dos preços de mercado, não havendo nenhuma falta de sensibilidade a estas flutuaçóes, mas uma forma própria de fazer face a elas (GARCIA Jr., 1983, p.129). 
Como já foi mencionado, o objetivo da produção para o autoconsumo é garantir autonomia da produção. Gazolla, Grisa e Schneider (2010) destacam, no entanto, outros dois sentidos para o autoconsumo. $\mathrm{O}$ primeiro diz respeito a ser uma fonte de renda náo monetária, e o outro, em relação à diversificação dos meios de vida, isto é, à estabilidade econômica das famílias rurais.

Gazolla, Grisa e Schneider (2010, p. 71), afirmam que “a diminuição do autoconsumo não significa maior mercantilização da agricultura e, do mesmo modo, maior mercantilização da agricultura não é sinônimo de redução do autoconsumo alimentar”. Em síntese, não há uma relação entre a produção com o processo. Esse aspecto se inverte um pouco da perspectiva de que a agricultura comercial é foco daqueles que vendem para a produção e adquirem seus bens no mercado. Destaca-se que a produção para o autoconsumo pode estar atrelada à própria condição da propriedade, ou seja, à estrutura, ferramentas, conhecimento e técnicas que permitem ou não produzir bens para a família.

Ainda, os aspectos culturais também são considerados determinantes na produção para o autoconsumo. Vander Ploeg apud Gazolla, Grisa e Schneider (2010, p. 71) define os fatores culturais como "um conjunto de noçóes estratégicas que guiam as açôes práticas e o comportamento dos agricultores. Trata-se de um modelo de tomada de decisão que é amiúde partilhado por um amplo número de agricultores, onde é discutido e transformado”.

Segundo esses autores, o repertório cultural dos agricultores de hoje não é o mesmo em comparação às propriedades de antigamente, que eram menos inseridas nos mercados. Nesse sentido, a produção para o autoconsumo é considerada uma herança que vem de casa. Assim, nas regiôes ou municípios em que são preservados os tradicionais hábitos de seus descendentes, a produção para o autoconsumo é mantida.

Para Schneider (2003), existem três fatores principais que determinam a produção para o autoconsumo: a segurança alimentar (o não uso de agrotóxico e a procedência dos alimentos), a questão da renda monetária que se origina a partir dessa produção e, por último, o aspecto da sociabilidade - a inserção social na qual ocorre a troca de produtos entre vizinhos.

Acrescentando, "a produção para o autoconsumo alimenta sociabilidades, firma relaçooes entre vizinhos, estabelece compromissos, consolida a vida comunitária e uma estrutura social importante para reprodução social das unidades familiares" (GRISA; SCHNEIDER, 2008, p. 489).

Ainda existem outros fatores que podem influenciar as características dessa produção. São os tipos de cultivos agrícolas nas propriedades. Trata-se de cultivos intensivos com mão de obra, como: a vitivinicultura, a piscicultura e a produção leiteira. Por fim, outro aspecto relevante é a logística, a proximidade ou a distância dos centros comerciais. $\mathrm{O}$ transporte público ou veículo particular são facilitadores aos agricultores para adquirirem produtos nos mercados, além dos preços de muitos alimentos serem-lhes atrativos (GAZOLLA, GRISA; SCHNEIDER, 2010).

A mensuração do autoconsumo se baseia no produto bruto e não líquido, por ser muito difícil separar a parte dos custos que englobam a produção. Com isso, não se pode afirmar que existe uma forma única ou mais adequada para se mensurar o autoconsumo, pois todas 
as maneiras possuem suas vantagens e desvantagens, potencialidades e limitações. Analisar uma propriedade da agricultura familiar com base nos conceitos e princípios utilizados para medir a eficiência de uma empresa capitalista está incorreto pois os produtores organizam o seu trabalho e a produção náo com o objetivo de obter lucro, e sim, de garantir o bem-estar de sua família (GAZOLLA; GRISA; SCHNEIDER, 2010).

Em síntese, a produção para autoconsumo é o ato de produzir das propriedades rurais, para consumo das famílias e que possui três aspectos centrais aqui identificados como preponderantes na decisão da produção: a perspectiva da renda dos produtores não gasta em itens que deixam de ser comprados; a segurança alimentar na produção, já que o produtor conhece aquilo que está produzindo, conhecendo a procedência dos alimentos, e; a sociabilidade produtiva na troca de produtos entre famílias próximas. Os referidos aspectos são os avaliados teórica e empiricamente no presente artigo.

\section{Procedimentos metodológicos}

Em termos de procedimentos metodológicos, esta pesquisa é qualitativa e quantitativa. Qualitativa pois visou a obter mais compreensão sobre o tema em estudo (ANDRADE, 2003), e assim proporcionar melhor visão e compreensão do contexto do problema analisado (MALHORTA, 2001). Ou seja, o trabalho trouxe à discussão os fatores que determinam a produção para o autoconsumo nas propriedades rurais de Teutônia/RS. É qualitativa pois discutiu as percepçóes dos agricultores, destacou quais fatores lhes eram representativos. E é quantitativa pois utilizou métodos quantitativos para calcular a renda não gasta quando da produção para autoconsumo.

Quanto aos fins da pesquisa, trata-se de um trabalho exploratório. Nesse sentido, se pesquisou o tema, a fim de se obter mais conhecimento e identificar os fatores que determinam a produção para o autoconsumo nas propriedades rurais.

A população deste estudo é formada pelos membros familiares das propriedades rurais que possuem produção integrada ou produção não integrada à agroindústria em Teutônia/RS. Foram escolhidas aleatoriamente algumas propriedades, a partir de encontro de mulheres filiadas ao Sindicato de Trabalhadores Rurais do Município.

Segundo dados de 2013 da Emater, o número de propriedades rurais de Teutônia/ RS era 1.029, número elevado para ser realizada a entrevista proposta neste estudo. Por isso, foram definidas como universo da populaçáo as participantes do encontro de mulheres do STR. A partir desse universo, foi usada uma amostra para o levantamento dos dados necessários para o estudo. As consideraçóes, no entanto, não poderão ser utilizadas de forma geral, uma vez que a pesquisa se refere, especificamente, às participantes do município pesquisado.

O encontro ocorreu no mês de setembro de 2015. Nele foi apresentada a proposta do estudo e solicitada a contribuição das agricultoras. Estavam presentes 40 agricultoras. Anotou-se contato para agendamento da entrevista das que se propuseram a participar do estudo. Ao final foram marcadas 10 entrevistas, devido à saturação na obtenção das informações. 
Quanto aos procedimentos de coleta de dados, é uma pesquisa bibliográfica, considerando que "a principal vantagem da pesquisa bibliográfica reside no fato de permitir ao investigador a cobertura de uma gama de fenômenos muito mais ampla do que aquela que poderia pesquisar diretamente" (GIL, 2012, p. 50), além de possibilitar consolidar conceitos para a problematização empírica.

Também foram consultados documentos, informaçóes e dados que caracterizam as propriedades rurais do município, número da população rural, principais atividades desempenhadas pelas famílias, dados estes obtidos no site do IBGE e em relatórios do STR de Teutônia/RS.

Por fim, a coleta de dados se deu por meio de uma pesquisa de campo. Esta é a ferramenta que se utiliza para buscar informaçóes ou conhecimentos sobre um problema a partir do qual se busca uma resposta (LAKATOS; MARCONI, 2002). Nesse sentido, o presente estudo englobou entrevistas em profundidade, atendendo aos seus objetivos propostos.

Ainda, em concordância com Lakatos e Marconi (2002, p. 83), a pesquisa de campo "consiste na observação de fatos e fenômenos tal como ocorrem espontaneamente, na coleta de dados a eles referentes e no registro de variáveis que se presume relevante, para analisálos".

As entrevistas, com perguntas de cunho semiestruturado, foram realizadas no segundo semestre de 2015. As questôes foram definidas pelos autores, baseadas em categorizações próprias e tratadas especificamente para este trabalho. Ainda, as dimensões das questôes são explicitadas no capítulo 06 , momento no qual são analisados os dados.

Genericamente, no primeiro plano definiram-se perguntas relacionadas às características dos membros da família residentes na propriedade. Após, perguntas direcionadas à propriedade e às atividades desempenhadas. Em seguida quanto aos gastos da família e, por último, à finalidade da produção para o autoconsumo e a percepção dessa produção.

Enfatiza-se que a entrevista foi previamente testada em duas propriedades do município que não participaram da coleta de dados da pesquisa e com a presidente do STR, para que se pudesse analisar melhor a estrutura das questôes.

Outra questáo a ser pontuada é que as entrevistas foram aplicadas preferencialmente com a mulher da casa, considerando que são elas que cuidam principalmente dos afazeres domésticos e da alimentação da família. Porém, em algumas entrevistas, a presença do homem e dos filhos foi permitida pela mulher não se sentir à vontade ao estar sozinha para responder os questionamentos.

A realização de somente 10 entrevistas se dá pela saturação, visto que, a partir de certo número de entrevistas, as respostas resultam em um mesmo significado, sem a inclusão de novos fatores à pesquisa. Assim, "a saturação designa o momento em que o acréscimo de dados e informaçóes em uma pesquisa não altera a compreensão do fenômeno estudado. É um critério que permite estabelecer a validade de um conjunto de observaçôes" (CHERQUES, 2009, p. 21). 
Após a coleta dos dados, ocorreu a etapa de análise. O processo de analisar os dados significa sistematizar todo o material que se obteve a partir das entrevistas e de documentos.

Todas as entrevistas foram gravadas com o objetivo de facilitar a análise das respostas. Posteriormente, os conteúdos de relevância das entrevistas foram transcritos e organizados conforme $\mathrm{o}$ assunto, ou seja, categorias que eram relevantes para o estudo. Foram destacados, além da identificaçáo da propriedade e da unidade familiar, aspectos que discutem as questôes de renda, de segurança alimentar e de interação social.

Por fim, os autores têm ciência que as pesquisas qualitativas possuem restriçóes, pois nâo podem ser transportadas para o âmbito mais geral. Além disso, as análises podem não abranger todos os aspectos possíveis de serem avaliados nesse contexto. No entanto, a pesquisa se propôs a avaliar os fatores que eram relevantes para os agricultores na produçáo para o autoconsumo, e é nestas condiçóes que é apresentada.

$\mathrm{Na}$ próxima etapa constam a caracterização das propriedades rurais do município de Teutônia/RS e, a seguir, os resultados obtidos e suas respectivas análises, divididos em tópicos específicos.

\section{As propriedades rurais do município de Teutônia/RS}

A regiáo do Vale do Taquari tem suas primeiras referências históricas em 1635, com as expediçôes dos Padres Gimenez e Soares, e em 1636, com as do bandeirante Raposo Tavares. Já em 1800 surgiram as primeiras fazendas de erva-mate, lavouras de cereais, criação de animais e exploração de madeiras, estas localizadas às margens do rio Taquari (SANTOS, 2015).

Em 1809, a regiáo do Vale do Taquari passou a pertencer ao município de Rio Pardo. Em 1849 se emancipou de Triunfo o município de Taquari, sendo considerado o municípiomãe da região. Em 1856, com a chegada dos primeiros colonos alemães, foi fundada a fazenda Estrela, originando, em 1876, o município de Estrela, do qual se emanciparam Lajeado e Teutônia (SANTOS, 2015).

O Vale conta com uma diversificação de descendestes de imigrantes europeus, como os portugueses, os alemães e os italianos, cada um com suas tradiçôes e folclore dos países de origem. $\mathrm{O}$ minifúndio se destaca nas propriedades rurais.

O Vale do Taquari, composto por 36 municípios, está localizado na regiáo central do Rio Grande do Sul, às margens do rio Taquari e afluentes, conforme a área de abrangência do Conselho de Desenvolvimento do Vale do Taquari - CODEVAT. A população do Vale em 2014 era estimada em 348.435 habitantes, conforme a Fundação de Economia e Estatísticas (FEE), o que representa 3,08\% da população gaúcha, sendo distribuída $73,84 \%$ da população na área urbana e $26,16 \%$ no meio rural. A economia da regiáo do Vale do Taquari é caracterizada nos municípios menores pela atividade agropecuária, e pela produção primária, enquanto em municípios maiores predominam as atividades ligadas à indústria e ao setor de serviços e comércio.

A história de Teutônia está relacionada com a imigração alemã, iniciada em 1824 com a criação da colônia alemã de São Leopoldo. O comerciante Carlos Schilling fundou 
a colônia de Teutônia em 1858, a partir da aquisição de terras. Nos anos de 1865/1866 chegaram em Teutônia os primeiros colonos, a grande maioria vinda da antiga zona colonial de Sáo Leopoldo (IBGE, 2015).

Com a formação das primeiras comunidades, como picada da Boa Sorte (hoje bairro Canabarro), picada Hermann (atualmente linha Germano), picada Boa Vista, picada Frank, picada Schmidt, picada Clara, picada Welp e picada Catarina, inicia-se o desenvolvimento da colônia, que já contava com 2.241 habitantes. Em 24 de maio de 1981, ocorreu a emancipação do município de Estrela, tornando-se uma das principais economias da regiáo do Vale do Taquari, no qual está inserido.

Estima-se uma população de 30.170 habitantes em $2015^{5}$, dos quais $85,52 \%$ (25.801) estão inseridos no meio urbano e 14,48\% (4.369) no meio rural (IBGE, 2015). O município de Teutônia é a segunda economia entre os 36 municípios filiados à Associação dos Municípios do Vale do Taquari (Amvat), de acordo com o índice de retorno do Imposto sobre Circulação de Mercadorias e Serviços (ICMS). A base da economia é a produção agropecuária, destacando-se a produção de leite, frangos e suínos, além do cultivo de milho e soja, seguido de produtos de subsistência como feijão, aipim, batata e hortaliças, que representam 20\% na arrecadação de ICMS. A indústria representa 49\%, enquanto o setor de serviços, 17\% e o comércio, 14\% (EMATER-RS, 2013).

O tamanho médio da área das propriedades rurais familiares no município é 8,8 hectares, característica do minifúndio. Conforme a Emater-RS de Teutônia (2013), são 1.029 propriedades rurais, das quais $62 \%$ possuem de 5 a 20 hectares. Ainda, de acordo com dados da Emater, essas propriedades rurais estão divididas em 928 propriedades de agricultura familiar e 101 propriedades de agricultura não familiar (empresarial). Como mencionado anteriormente, a população rural, estimada em 4.369 habitantes, é representada por 2.203 homens e 2.166 mulheres.

No município existem algumas políticas públicas em execução: no âmbito municipal - o Pacote Agrícola, o Auxílio Agroindústria e o Auxílio Construção; em nível estadual - o Mais Água Mais Renda, o Leite Gaúcho e a Agroindústria Familiar; e em escala federal - o Bolsa Família e o Pronaf.

\section{Produzir para autoconsumo: os resultados empíricos}

A análise dos dados está dividida em três subtítulos principais, sendo, nas características das propriedades e das entrevistadas, descritas a função das participantes do estudo no núcleo familiar, sua escolaridade, número de pessoas na família, ocupação profissional dos membros da família, renda, período que vivem na propriedade, forma de aquisição da propriedade, atividades desenvolvidas, tamanho da propriedade e se participam de sistema integrado de produção. Relacionando a percepção passado versus presente, são discutidas as percepçóes da produção para autoconsumo no tempo dos pais das entrevistadas (como plantavam, o que produziam e se compravam), se houve mudanças nessa produção considerando os

5 Fonte: IBGE. Diretoria de Pesquisas - DPE - Coordenação de População e Indicadores Sociais - Copis. 
dias atuais, e se hoje a alimentação é melhor que antigamente. Na questão da atualidade, a respeito do autoconsumo, são analisados o que os produtores produzem, se possuem noção da renda náo monetária caso os comprassem e os fatores que determinam essa produção.

\subsection{Características das propriedades e entrevistadas}

Nas 10 entrevistas em análise, a maioria das propriedades, sete delas, possuem como característica o minifúndio, com área de até 18 hectares, porém as propriedades $\mathrm{D}, \mathrm{G}$ e I possuem área maior, não se enquadrando como minifúndio ${ }^{6}$, e sim como pequenas propriedades $^{7}$. Em relação à posse da terra, tem-se que nos comentários das entrevistas observou-se a dificuldade que havia antigamente para produzir e adquirir algo. Hoje há mais facilidade, se considerada a disponibilidade de financiamentos ao agricultor. Contudo, na pesquisa, conforme as pesquisadas, somente a propriedade A foi comprada, as demais foram herdadas, como demonstrado na Tabela 1 .

Tabela 1 - Características das propriedades pesquisadas

\begin{tabular}{c|c|c|c|c|c}
\hline Propriedade & $\begin{array}{c}\text { Período que a } \\
\text { entrevistada vive na } \\
\text { propriedade }\end{array}$ & $\begin{array}{c}\text { Aquisiçáo da } \\
\text { propriedade }\end{array}$ & $\begin{array}{c}\text { Área } \\
\mathbf{( H a )}\end{array}$ & $\begin{array}{c}\text { Principal } \\
\text { produçáo }\end{array}$ & $\begin{array}{c}\text { Propriedade } \\
\text { integrada }\end{array}$ \\
\hline A & Acima de 18 anos & Comprada & 8 & Leite & Não \\
\hline B & Acima de 18 anos & Herdada & 18 & Leite e lavoura & Não \\
\hline C & Acima de 18 anos & Herdada & 12 & Leite & Náo \\
\hline D & Acima de 18 anos & Herdada & 22 & Leite e suínos & Sim \\
\hline E & Acima de 18 anos & Herdada & 9 & Leite & Náo \\
\hline F & Acima de 18 anos & Herdada & 6 & Leite & Náo \\
\hline G & Acima de 18 anos & Herdada & 24 & Leite & Não \\
\hline H & Acima de 18 anos & Herdada & 11 & Leite e aves & Sim \\
\hline I & Acima de 18 anos & Herdada & 22 & Leite e aves & Sim \\
\hline J & Acima de 18 anos & Herdada & 8 & Leite, suínos & S aves \\
\hline
\end{tabular}

Fonte: Dos autores, com base nos dados da pesquisa.

Uma característica predominante em todas as propriedades é o período em que as entrevistadas vivem nelas, ou seja, acima de 18 anos. Isso significa que, certamente, as participantes do estudo são a segunda geração a morar na propriedade, especialmente por esta ser herdada. Até mesmo a propriedade que foi comprada está na segunda geração. Outro ponto relevante é que todas as propriedades trabalham com a produção de leite, uma característica da regiáo do Vale do Taquari.

6 Minifúndio: imóvel rural de área inferior a um módulo fiscal, o que corresponde no município de Teutônia a 18 ha.

7 Pequenas propriedades: imóvel rural de área compreendida entre um e quatro módulos fiscais. 
Em se tratando de escolaridade, a maioria das entrevistadas possui o ensino fundamental completo. Nas propriedades D, H, I e J, as entrevistadas concluíram o ensino médio, sendo mulheres jovens, com idade entre 26 a 43 anos. As mulheres mais velhas, quando em "idade escolar", tinham mais dificuldade para ir à escola, como cita uma integrante da propriedade A:

“(...) era longe para ir à escola, e tinha que ir a pé. E naquele tempo os meus pais queriam que eu ajudasse em casa."

Tabela 2 - Características das entrevistadas

\begin{tabular}{|c|c|c|c|c|}
\hline Propriedade & $\begin{array}{c}\text { Ocupaçáo no } \\
\text { núcleo familiar }\end{array}$ & Escolaridade & $\begin{array}{c}\text { Número de } \\
\text { pessoas na família }\end{array}$ & Ocupaçáo profissional \\
\hline A & Vó & $\begin{array}{c}\text { Ensino } \\
\text { Fundamental }\end{array}$ & 2 & $\begin{array}{l}\text { Todos trabalham na } \\
\text { propriedade }\end{array}$ \\
\hline B & Nora & $\begin{array}{c}\text { Ensino } \\
\text { Fundamental }\end{array}$ & $5^{*}$ & $\begin{array}{l}\text { Todos trabalham na } \\
\text { propriedade }\end{array}$ \\
\hline $\mathrm{C}$ & Filha & $\begin{array}{c}\text { Ensino } \\
\text { Fundamental }\end{array}$ & 5 & Um membro trabalha fora \\
\hline $\mathrm{D}$ & Nora & Ensino Médio & 6 & $\begin{array}{l}\text { Todos trabalham na } \\
\text { propriedade }\end{array}$ \\
\hline $\mathrm{E}$ & Mãe & $\begin{array}{c}\text { Ensino } \\
\text { Fundamental }\end{array}$ & 4 & $\begin{array}{l}\text { Dois membros trabalham } \\
\text { fora }\end{array}$ \\
\hline $\mathrm{F}$ & Mãe & $\begin{array}{c}\text { Ensino } \\
\text { Fundamental }\end{array}$ & 5 & $\begin{array}{l}\text { Dois membros trabalham } \\
\text { fora }\end{array}$ \\
\hline G & Mãe & $\begin{array}{c}\text { Ensino } \\
\text { Fundamental }\end{array}$ & 2 & $\begin{array}{l}\text { Todos trabalham na } \\
\text { propriedade }\end{array}$ \\
\hline $\mathrm{H}$ & Filha & Ensino Médio & 4 & $\begin{array}{l}\text { Todos trabalham na } \\
\text { propriedade }\end{array}$ \\
\hline I & Nora & Ensino Médio & 5 & $\begin{array}{l}\text { Todos trabalham na } \\
\text { propriedade }\end{array}$ \\
\hline $\mathrm{J}$ & Mãe & Ensino Médio & 4 & $\begin{array}{l}\text { Todos trabalham na } \\
\text { propriedade }\end{array}$ \\
\hline
\end{tabular}

Fonte: Dos autores com base nos dados da pesquisa.

Nota $\left({ }^{*}\right)$ : Significa que somente dois trabalham. As demais pessoas que compóem a família são um casal de idosos e uma criança.

Nas entrevistas, em geral, todos os membros aptos ${ }^{8}$ trabalham na propriedade, exceto na propriedade $\mathrm{C}$, em que um membro trabalha fora, e nas propriedades $\mathrm{E}$ e $\mathrm{F}$, das quais dois membros trabalham em outra atividade. É, como Schneider (2003) menciona, a questáo da pluriatividade, pois nessas propriedades os membros buscaram outras formas de rendimentos fora da propriedade. Também observa-se na Tabela 2 o número de duas a seis pessoas por residência, variando conforme a atividade. Nas propriedades com mais de uma atividade, observa-se maior número de membros, exceto na propriedade B.

8 Pessoas que possuem condições para trabalhar, ou seja, que não são crianças ou idosos. 


\subsection{Percepção passado versus presente}

Durante as entrevistas, pôde-se constatar semelhança nas colocaçóes sobre a produção para o autoconsumo na época dos pais das entrevistadas e na atual. Relatam que antigamente praticamente plantavam e produziam de tudo, sendo comprado somente o que não conseguiam realmente produzir, como o sal e o café. Assim expressou-se a entrevistada da propriedade $\mathrm{G}$ sobre esse tema:

“(...) plantava praticamente tudo. Como a familia era grande naquele tempo, cada um podia fazer um pouco. De inicio nem café se comprava, se fazia com batata-doce torrada, mas depois de um tempo a mãe não queria mais, ai começou a se comprar fora..."

Também a integrante da propriedade A relata:

“(...) se plantava de tudo, um pouco de cada coisa. Naquela época nem leite se vendia, pois ninguém coletava - só depois de um tempo que começou. Se plantava trigo e se fazia a própria farinha e arroz. Era tudo bem saudável. Só a aparência não era como é hoje..."

Todas foram enfáticas ao afirmar que houve mudança em sua alimentação em comparação com o tempo de seus pais, melhorando-a em termos de variedades, mas valendo-se de produtos industrializados. Somente a entrevistada da propriedade G relata que mantém a mesma alimentação:

“(..) sou muito apegada às coisas do passado. Hoje se compra muitos produtos enlatados. Aqui nunca foi costume e nunca vamos ter, pois não gostamos, queremos sentir o sabor dos alimentos..."

Conforme o relato da entrevistada da propriedade E, “(...) hoje é tudo mais liberado. Antigamente a comida era mais controlada...”, referindo-se às mudanças na alimentação da época dos pais em relação à atual.

Já a Tabela 3 retrata se as refeições são feitas em família, quais são os maiores gastos e onde são adquiridos os alimentos, se comprados.

Tabela 3 - Características das refeições das famílias

\begin{tabular}{c|c|c|c}
\hline Propriedade & $\begin{array}{c}\text { Refeiçóes sáo feitas } \\
\text { conjuntamente }\end{array}$ & Maiores gastos & $\begin{array}{c}\text { Local de aquisiçáo dos } \\
\text { alimentos }\end{array}$ \\
\hline A & Todas as refeiçóes & $\begin{array}{c}\text { Supermercado e na } \\
\text { propriedade }\end{array}$ & $\begin{array}{c}\text { Supermercado e caminháo de } \\
\text { verduras }\end{array}$ \\
\hline B & Todas as refeições & Supermercado & $\begin{array}{c}\text { Supermercado e caminhão de } \\
\text { verduras }\end{array}$ \\
\hline C & A maioria das refeiçôes & $\begin{array}{c}\text { Supermercado e na } \\
\text { propriedade }\end{array}$ & $\begin{array}{c}\text { Supermercado e caminhão de } \\
\text { verduras }\end{array}$ \\
\hline D & A maioria das refeições & $\begin{array}{c}\text { Supermercado e na } \\
\text { propriedade }\end{array}$ & $\begin{array}{c}\text { Supermercado e caminháo de } \\
\text { verduras }\end{array}$ \\
\hline E & A minoria das refeições & $\begin{array}{c}\text { Supermercado e na } \\
\text { propriedade }\end{array}$ & Supermercado \\
\hline F & A maioria das refeições & Comércio & Supermercado \\
\hline G & Todas as refeições & $\begin{array}{c}\text { Supermercado e na } \\
\text { propriedade }\end{array}$ & Supermercado \\
\hline
\end{tabular}




\begin{tabular}{c|c|c|c}
\hline Propriedade & $\begin{array}{c}\text { Refeiçóes sáo feitas } \\
\text { conjuntamente }\end{array}$ & Maiores gastos & $\begin{array}{c}\text { Local de aquisiçáo dos } \\
\text { alimentos }\end{array}$ \\
\hline $\mathrm{H}$ & Todas as refeições & $\begin{array}{c}\text { Supermercado e na } \\
\text { propriedade }\end{array}$ & Supermercado \\
\hline $\mathrm{I}$ & Todas as refeições & $\begin{array}{c}\text { Supermercado e na } \\
\text { propriedade }\end{array}$ & Supermercado \\
\hline $\mathrm{J}$ & Todas as refeições & $\begin{array}{c}\text { Supermercado e na } \\
\text { propriedade }\end{array}$ & Supermercado \\
\hline
\end{tabular}

Fonte: Dos autores, com base nos dados de pesquisa.

Nas propriedades A, B, G, H, I e J, todos os membros trabalham na propriedade e realizam todas as refeiçóes juntos. Também na propriedade $\mathrm{D}$ todos trabalham na propriedade e a maioria das refeiçóes são feitas em conjunto. As demais propriedades, C, $\mathrm{E}$ e F, possuem algum membro trabalhando fora e, consequentemente, realizando alguma refeição distante da família.

Em todas as propriedades há horta e pomar, mas, mesmo assim, as entrevistadas das propriedades A, B, C e D compram algumas verduras e frutas de um caminhão de verduras que passa em suas propriedades. Assim justifica essa situação a entrevistada da propriedade A:

“(...) geralmente compramos alguma coisa do verdureiro, mas só quando não conseguimos produzir, pois algumas coisas só dão em certa época, então compramos dele, mas só em último caso...".

\subsection{Autoconsumo}

A produção para o autoconsumo é uma prática desenvolvida há muitos anos nas propriedades rurais. De acordo com Gazolla, Grisa e Schneider (2010), esta produção é uma herança que vem de casa, sendo mantida nos dias atuais. A proprietária da propriedade $\mathrm{G}$ assinala esse aspecto em seu depoimento:

“(..) fui criada pelos meus pais, onde (sic) plantávamos de tudo - só comprávamos fora o sal. Então até hoje mantenho isso. Só compro no supermercado produtos de limpeza e o essencial. O que eu conseguir produzir em casa vou fazer, mesmo sendo só em dois, pois fui ensinada assim...".

Como abordado anteriormente, todas as entrevistadas possuem em suas propriedades horta e pomar. Dentre as hortaliças, as cinco mais cultivadas pelas mulheres são alface, beterraba, cenoura, pepino e alho. Em relação às frutíferas, a produção de laranja e a de bergamota são as mais comuns entre as listadas. Outra dimensão de produção para o autoconsumo é a transformação caseira, sendo citados o queijo, o pão e a schmier. O Gráfico 1 retrata os produtos cultivados para o autoconsumo e o número de propriedades que os produzem. 
Gráfico 1 - Número de propriedades que produzem determinado produto, 2015

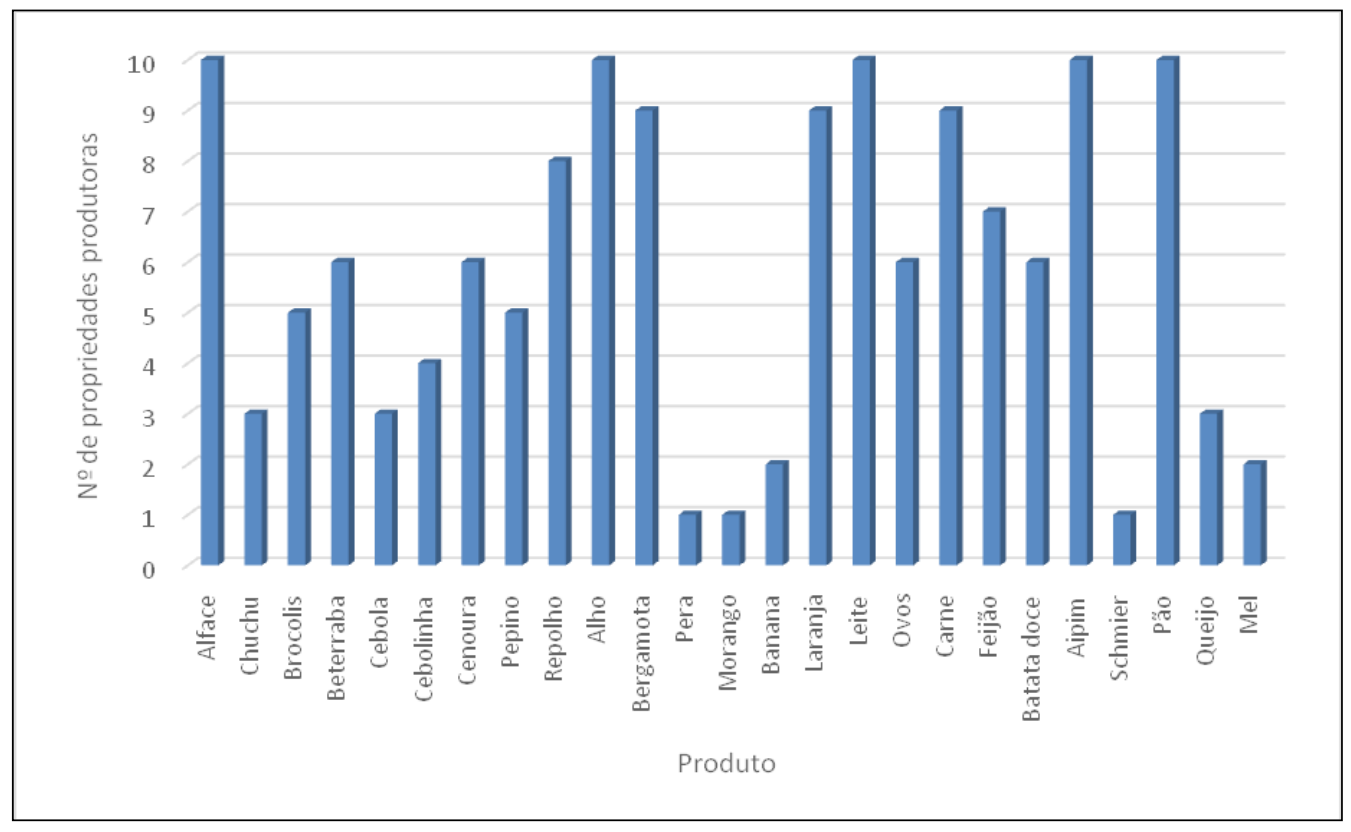

Fonte: Dos autores, com base nos dados da pesquisa.

Outra questão enfatizada nas entrevistas foram os fatores que determinam a produção para o autoconsumo, ou seja, por que as entrevistadas mantêm essa produçáo. As colocaçóes seguiram a mesma linha, todas explicitaram, primeiramente, a questão da segurança alimentar e, posteriormente, a renda. A produtora da propriedade I enfatiza:

“(...) sem dúvida, produzimos ainda porque sabemos o que estamos comendo, alimentos saudáveis, limpos de agrotóxicos (...), e ainda podemos colher quando precisamos. Assim temos sempre produtos fresquinhos...".

Acrescenta a produtora da propriedade J:

“(...) produtos naturais, sabemos o que temos na horta, e, quando colocamos na mesa, podemos comer sem preocupação de possuir veneno...”.

Sobre a produção para autoconsumo ser uma alternativa de renda não monetária, todas as entrevistadas consideraram que produzem também tendo em vista o preço. No entanto, quando questionadas se calculam quanto essa produção representa em valores, somente a entrevistada da propriedade $\mathrm{F}$ possuía uma noção de que gastaria em torno de $\mathrm{R} \$$ 500,00 por mês - as demais não fazem ideia de valores.

Para Gazolla e Schneider (2007), com a produção para o autoconsumo, os membros das famílias poderão se dedicar a outras atividades, obtendo assim outras fontes de renda, pois o valor economizado com o autoconsumo poderá ser aplicado na propriedade. Contudo, para que isso aconteça, os produtores precisarão ter noção de quanto essa produção rende na sua propriedade e, consequentemente, quanto representa a sua renda. 
O Quadro 1 demonstra os valores médios que cada propriedade gastaria caso comprasse em supermercados ou em outros estabelecimentos os alimentos citados no Gráfico 1, valor que poderá ser revertido para a propriedade. Os alimentos foram agrupados em: hortifruti; lácteos; carnes, ovos e mel; produtos oriundos da lavoura; e produtos de transformação caseira, com o objetivo de facilitar a compreensão dos valores por grupo.

Quadro 1 - Apuração dos valores dos produtos produzidos para o autoconsumo, por agrupamento

\begin{tabular}{|c|c|c|c|c|c|c|c|c|c|c|}
\hline $\begin{array}{l}\text { Propriedades } \\
\text { Produtos }\end{array}$ & A & B & C & D & $\mathbf{E}$ & $\mathbf{F}$ & $\mathbf{G}$ & $\mathbf{H}$ & I & $\mathbf{J}$ \\
\hline Hortifruti & $R \$ 106,55$ & $\mathrm{R} \$ 225,82$ & $\mathrm{R} \$ 263,17$ & $\mathrm{R} \$ 211,36$ & $\mathrm{R} \$ 212,10$ & $\mathrm{R} \$ 344,42$ & $\mathrm{R} \$ 121,97$ & $\mathrm{R} \$ 180,66$ & $\mathrm{R} \$ 244,36$ & $R \$ 164,96$ \\
\hline Lácteos & $\mathrm{R} \$ 21,66$ & $\mathrm{R} \$ 54,15$ & $\mathrm{R} \$ 54,15$ & $\mathrm{R} \$ 64,98$ & $\mathrm{R} \$ 43,32$ & $\mathrm{R} \$ 54,15$ & $\mathrm{R} \$ 21,66$ & $\mathrm{R} \$ 43,32$ & $\mathrm{R} \$ 54,15$ & $\mathrm{R} \$ 43,32$ \\
\hline Carne, ovos e mel & $\mathrm{R} \$ 100,87$ & $\mathrm{R} \$ 225,11$ & $\mathrm{R} \$ 212,00$ & $\mathrm{R} \$ 262,23$ & $\mathrm{R} \$ 174,81$ & $\mathrm{R} \$ 218,11$ & $\mathrm{R} \$ 2,44$ & $\mathrm{R} \$ 175,53$ & $\mathrm{R} \$ 212,00$ & $\mathrm{R} \$ 169,93$ \\
\hline $\begin{array}{l}\text { Produtos oriundos } \\
\text { da lavoura }\end{array}$ & $\mathrm{R} \$ 14,66$ & $\mathrm{R} \$ 36,67$ & $\mathrm{R} \$ 36,67$ & $\mathrm{R} \$ 11,20$ & $\mathrm{R} \$ 15,89$ & $\mathrm{R} \$ 36,67$ & $\mathrm{R} \$ 14,66$ & $\mathrm{R} \$ 7,46$ & $R \$ 36,67$ & $\mathrm{R} \$ 7,46$ \\
\hline $\begin{array}{l}\text { Transformaçáo } \\
\text { caseira }\end{array}$ & $\mathrm{R} \$ 35,54$ & $\mathrm{R} \$ 89,51$ & $\mathrm{R} \$ 61,40$ & $\mathrm{R} \$ 107,40$ & $\mathrm{R} \$ 49,10$ & $\mathrm{R} \$ 61,40$ & $\mathrm{R} \$ 35,79$ & $\mathrm{R} \$ 49,10$ & $\mathrm{R} \$ 61,40$ & $\mathrm{R} \$ 49,10$ \\
\hline $\begin{array}{l}\text { Total por } \\
\text { propriedade (R\$) }\end{array}$ & $\mathrm{R} \$ 279,28$ & $\mathrm{R} \$ \mathbf{6 3 1 , 2 6}$ & R\$ 627,39 & $\mathrm{R} \$ 657,17$ & $\mathrm{R} \$ 495,22$ & $\mathrm{R} \$ 714,75$ & $\mathrm{R} \$ 196,52$ & $\mathrm{R} \$ \mathbf{4 5 6 , 0 7}$ & $\mathrm{R} \$ \mathbf{6 0 8 , 5 8}$ & R\$ 434,77 \\
\hline
\end{tabular}

Fonte: Dos autores, com base nos dados da pesquisa.

Para apontar o valor que cada propriedade gera com a produção para autoconsumo, primeiramente identificaram-se os produtos produzidos. Com base na pesquisa de orçamentos familiares 2008 - 2009 (IBGE, 2015), apurou-se a quantidade média que cada pessoa consome de cada um desses produtos. Os valores de cada alimento foi obtido a partir de consultas em três diferentes supermercados no município de Teutônia, calculando-se o valor médio de cada um.

Observa-se que a representatividade do agrupamento carnes, ovos e mel é considerada alta em relaçáo aos demais produtos devido ao alto preço pago hoje em dia por esses alimentos. Mesmo diante dessa realidade, a entrevistada da propriedade $G$ não os produz para o seu consumo. Conforme ela,

“(...) paramos pois não vale mais a pena. A gente não come tanta carne. E, como somos só em dois em casa, ela sempre ficava velha e sem gosto. Entäo achamos melhor comprar fora, pois é mais viável...".

No que diz respeito à representatividade da produção para o autoconsumo nas rendas das famílias entrevistadas, conforme demonstrado na Tabela 4, observa-se que, na maioria, os valores giraram em torno de $10 \%$ da renda. Na propriedade F, no entanto, a representatividade é de $15,1 \%$, mesmo sendo uma propriedade pequena, de cinco hectares, possuindo somente a atividade leiteira e dois membros familiares trabalhando fora, sendo, portanto, uma produção expressiva. Mas, em contrapartida, na propriedade G, a representatividade na renda é baixa, $3 \%$, mas não significa que a família não se empenha para produzir, pelo contrário, o casal entrevistado se mostra orgulhoso em poder produzir seu próprio alimento, herança adquirida de seus pais. 
A baixa representatividade é justificada pelo número de membros na família, somente dois. Com isso produzem somente a quantidade da qual necessitam, além de comprarem a carne, o que representa muito em valor. Além disso, a atividade leiteira que desenvolvem é de grandes proporçóes.

O valor que a produção para autoconsumo representa na renda de cada propriedade foi obtido a partir da apuração do valor total médio que cada propriedade produz, conforme demonstrado na Tabela 4.

Tabela 4 - Representatividade da produção para o autoconsumo na renda familiar

\begin{tabular}{c|c|c|c}
\hline Propriedade & Renda $(\mathbf{R} \mathbf{)}$ & Valor da produçáo $(\mathbf{R} \mathbf{})$ & Representatividade (\%) \\
\hline A & $2.728,00$ & 279,28 & $10,1 \%$ \\
\hline B & $4.728,00$ & 631,26 & $13,4 \%$ \\
\hline C & $5.516,00$ & 627,39 & $11,4 \%$ \\
\hline D & $4.728,00$ & 657,17 & $13,9 \%$ \\
\hline E & $4.334,00$ & 495,22 & $11,4 \%$ \\
\hline F & $4.728,00$ & 714,75 & $15,1 \%$ \\
\hline G & $5.516,00$ & 196,52 & $3 \%$ \\
\hline H & $4.728,00$ & 456,07 & $9,6 \%$ \\
\hline I & $5.122,00$ & 608,58 & $11,9 \%$ \\
\hline J & $4.728,00$ & 434,77 & $9,2 \%$ \\
\hline
\end{tabular}

Fonte: Dos autores, com base nos dados de pesquisa.

Conforme os autores que abordam o autoconsumo, a importância do autoconsumo se deve a três razóes: a segurança alimentar, a alternativa de renda não monetária e a questão da sociabilidade. Este último motivo não é apontado em nenhuma das 10 entrevistas. A entrevistada da propriedade $\mathrm{E}$ assim explica o motivo pelo qual não há troca de alimentos com os vizinhos:

“(...) o pessoal não se dá o tempo de plantar. É mais fácil ir comprar. E hoje vivem em cima das máquinas. Então em qualquer espaço plantam lavoura...".

Acrescenta a entrevistada da propriedade $\mathrm{H}$ :

“(...) os jovens que administram as propriedades não pensam nisso. Preferem ir no mercado e comprar. Tem vizinho que não planta nenhum pé de alface e cebolinha. É uma vergonha estar no meio rural e náo plantar. Por isso que náo trocamos mais...".

Mesmo com os incentivos do STR e da Emater, a produção para o autoconsumo está diminuindo. As novas gerações não estão preocupadas em manter essa característica das propriedades, principalmente pelas atividades que desempenham e as facilidades de adquirir os alimentos, além da proximidade de oferta de produtos. 


\section{Consideraçóes finais}

Com a realizaçáo do presente estudo, puderam-se analisar os fatores que levam os produtores rurais a produzirem para o autoconsumo em seus empreendimentos rurais. Nas 10 pesquisas realizadas em propriedades com características diversas, foi possível verificar, de maneira global, como os produtores administram essa produção.

É indiscutível a importância da agricultura familiar na economia da região e também do país. No município de Teutônia, onde foi realizado o estudo, $90 \%$ das propriedades rurais são de agricultura familiar. No município, a média do tamanho das áreas das propriedades são em torno de 8,8 ha, o que as caracterizam como propriedades pequenas, mas que representam mais de $20 \%$ do ICMS do município.

Quanto à produção para autoconsumo na época dos pais das entrevistadas, todas afirmaram que se produzia muito mais alimentos do que hoje, devido à disponibilidade da mão de obra (as famílias eram maiores), a grande distância do comércio e a dificuldade em se locomover, além da troca de produtos com os vizinhos, a chamada inserção social.

Todas as entrevistadas desenvolvem a produção para o autoconsumo em suas propriedades, mantendo horta e pomar, mas cada uma com suas peculiaridades e intensidades. Conforme as entrevistadas, trata-se de algo indispensável na obtenção de alimentos fresquinhos e sem agrotóxicos. O que varia são os produtos produzidos, sua quantidade e os fatores que impossibilitam a sua produção. Os alimentos que mais foram citados na pesquisa são: carne, ovos, batata-doce, aipim, leite, feijão, além da horta e do pomar.

Outro aspecto a ressaltar, que é abordado em outras pesquisas de diversos autores, trata-se dos três principais fatores para a produção dos alimentos para o consumo familiar, que são a segurança alimentar, a renda não monetária e a inserção social. Sobre esse aspecto observaram-se, nos apontamentos das entrevistadas, a qualidade dos alimentos sem o uso de agrotóxicos (segurança alimentar) e produtos com custos mais baixos. Nenhuma das entrevistadas mencionou a troca de produtos com os vizinhos, pois algumas propriedades não produzem mais ou somente o essencial. Além disso, as gerações mais novas não possuem mais contato com os vizinhos como seus pais e avós mantinham.

Quanto à representatividade da produção para o autoconsumo nas rendas das famílias, constatou-se que, nas propriedades, a produção para o autoconsumo representa, em média, $10 \%$ na renda das famílias. Pode-se considerar um valor relevante, visto que na maioria das propriedades não é calculado o valor final, somente o fato de ser mais barato produzir do que comprar.

Embora haja incentivos do Sindicato, da Emater e da prefeitura para que essa produção continue nas propriedades, os agricultores familiares estão cada vez mais diversificando suas atividades e, por exigência das empresas integradoras, dependendo da atividade exercida, não é permitido que se produza no ambiente familiar ou artesanalmente. 


\section{Referências}

ABRAMOVAY, Ricardo. O futuro das regióes rurais. Porto Alegre: Editora da UFRGS, 2003.

ANDRADE, Maria Margarida de. Introduçáo à metodologia do trabalho científico: elaboração de trabalhos na graduação. 6. ed. São Paulo: Atlas, 2003.

ANDRADE, José Geraldo de et al. A administraçáo da fazenda. 3. ed. São Paulo, 1990. ARAUJO, Massilon J. Fundamentos de agronegócios. São Paulo: Atlas, 2009.

BRASIL. Lei no 11.326 de 24 de julho de 2006. Disponível em: <http://www.planalto. gov.br/ccivil_03/_Ato2004-2006/2006/Lei/L11326.htm>. Acesso em: 29 ago. 2015.

CHERQUES, Hermano Roberto Thiry. Saturação em pesquisa qualitativa: estimativa empírica de dimensionamento. Revista PMKT 03, completa 4 cores: Layout 1, 2009.

CNA - Confederação da Agricultura e Pecuária do Brasil. Agronegócio. Disponível em: <http://www.faculdadecna.com.br/agronegocio\#.VeJIDSVViko>. Acesso em: 29 ago. 2015 .

EMATER-RS- Associação Rio-grandense de Empreendimentos de Assistência Técnica e Extensão Rural. Estudo de situação. Teutônia, 2013.

FEE - Fundação de Economia e Estatística. Perfil socioeconômico.

Disponível em: <http://www.fee.rs.gov.br/perfil-socioeconomico/coredes/ detalhe/?corede=Vale+do+Taquari $>$. Acesso em: 14 set. 2015.

FEIJÓ, Ricardo Luis Chaves. Economia agrícola e desenvolvimento rural. Rio de Janeiro: LTC, 2011.

FLORES, Aécio Witchs; RIES, Leandro Reneu; ANTUNES, Luciano Medici. Gestão rural. Porto Alegre: Ed. dos Autores, 2006.

GAZOLLA, Marcio; SCHNEIDER, Sergio. A produção da autonomia: os "papéis" do autoconsumo na reprodução social dos agricultores familiares. Estud. Soc. Agric. Rio de Janeiro, v. 15, n.1, 2007.

GAZOLLA, Marcio; GRISA, Catia; SCHNEIDER, Sergio. A “produção invisível” na agricultura familiar: autoconsumo, segurança alimentar e políticas públicas de desenvolvimento rural. Agroalimentaria, v.16, n. 31. Impresso em julho-dezembro de 2010.

GARCIA Jr, Afranio Raul. Terra de trabalho: trabalho familiar de pequenos produtores. Rio de Janeiro: Editora Paz e Terra, 236p., 1983. 
O sul: caminho do roçado: estratégias de reprodução camponesa e transformação social. Marco Zero: São Paulo; Brasília, DF, Editora Universitária de Brasília; MCTCNPq, 285p., 1989.

GIL, Antonio Carlos. Métodos e técnicas de pesquisa social. 6. ed. São Paulo: Atlas, 2012.

GRISA, Catia; SCNEIDER, Sergio. "Plantar pro gasto": a importância do autoconsumo entre famílias de agricultores do Rio Grande do Sul. Piracicaba- SP, v. 46, n. 02. Impresso em junho 2008 .

IBGE - Instituto Brasileiro de Geografia e Estatística. Censo Agropecuário de 2006. Disponível em: <http://www.ibge.com.br>. Acesso em: 29 ago. 2015.

IBGE - Instituto Brasileiro de Geografia e Estatística. Histórico de Teutônia. Disponível em: <http://www.cidades.ibge.gov.br/painel/historico.php?lang=\&codmun=432145>. Acesso em: 11 out. 2015.

IBGE - Instituto Brasileiro de Geografia e Estatística. Pesquisa de Orçamentos Familiares 2008-2009: Aquisição alimentar domiciliar per capita anual. Disponível em: $<$ http://www.ibge.gov.br/estadosat/temas.php?sigla=rs\&tema=pofaquisicaoalimentar $>$. Acesso em: 11 out. 2015.

INCRA - Instituto Nacional de Colonização e Reforma Agrária. Classificação dos imóveis rurais. Disponível em: <http://www.incra.gov.br/tamanho-propriedades-rurais>. Acesso em: 31 ago. 2015.

. Estrutura Fundiária. Disponível em: <http://www.incra.gov.br/sites/default/ files/uploads/estrutura-fundiaria/regularizacao-fundiaria/indices-cadastrais/indices_ basicos_2013_por_municipio.pdf>. Acesso em: 31 ago. 2015.

LAKATOS, Eva Maria; MARCONI, Marina de Andrade. Técnicas de pesquisa: planejamento e execução de pesquisas, amostragens e técnicas de pesquisas, elaboração, análise e interpretação de dados. 5. ed. São Paulo: Atlas, 2002.

LAMARCHE, H. A agricultura familiar: comparação internacional, uma realidade multiforme. Campinas: Unicamp, 1993.

MALHORTA, K. Naresh K. Pesquisa de marketing: uma orientação aplicada. 3. ed. Porto Alegre: Bookman, 2001.

REZENDE FILHO, Cyro de Barros. História econômica geral. São Paulo: Contexto, 2000. 
SANTOS, Airton Engster do. Vale do Taquari - entre vales e montanhas do Rio Grande do Sul. Disponível em: <http://www.overmundo.com.br/banco/vale-do-taquari-entrevales-e-montanhas-do-rio-grande-do-sul>. Acesso em: 11 out. 2015.

SCHNEIDER, Sergio. A pluriatividade na agricultura familiar. Porto Alegre: Editora da UFRGS, 2003.

SILVA, Roni Antonio Garcia da. Administração rural: teoria e prática. 2. ed. Curitiba, 2011. 